\title{
Reply to Dr. Rekate's comments on our article "Acute ventriculoperitoneal shunt malfunction following opening of the spinal subarachnoid space: a case series"
}

\author{
R. Shane Tubbs $\cdot$ W. Jerry Oakes
}

Received: 24 June 2009/Published online: 24 July 2009

(C) Springer-Verlag 2009

\section{Dear Editor:}

We would like to thank Dr. Rekate for his interest in our paper [1]. To address Dr. Rekate's two points we offer the following:

(1) The word "siphon" was used once in our abstract and was not used in the mechanical sense but rather in a colloquial manner to simply mean to "convey, draw or pass".

(2) Each of the ventricular catheters from the patients reported were placed in a standard position and in no patient was intracranial pressure found to be negative based on intraoperative testing, which is routine for all of our shunt revisions.

\section{Reference}

1. Tubbs RS, Pugh J, Cakpo-Satchivi L, Wellons JC III, Blount JP, Oakes WJ (2009) Acute ventriculoperitoneal shunt malfunction following opening of the spinal subarachnoid space: a case series. Childs Nerv Syst 25:599-600

R. S. Tubbs $(\bowtie) \cdot$ W. J. Oakes Section of Pediatric Neurosurgery, Children's Hospital, ACC 400, 1600 7th Ave South, Birmingham, AL 352333, USA

e-mail: rstubbs@uab.edu 